\title{
Family planning use and its associated factors among women in the extended postpartum period in Addis Ababa, Ethiopia
}

Almaz Yirga Gebremedhin ${ }^{1 *}$, Yigzaw Kebede ${ }^{2}$, Abebaw Addis Gelagay ${ }^{3}$ and Yohannes Ayanaw Habitu ${ }^{3}$

\begin{abstract}
Background: Postpartum period is an important entry point for family planning service provision; however, women in Ethiopia are usually uncertain about the use of family planning methods during this period. Limited studies have been conducted to assess postpartum family planning use in Addis Ababa, in particular and in the country in general. So, this study was conducted to assess postpartum family planning use and its associated factors among women in extended postpartum period in Kolfe Keranyo sub city of Addis Ababa.

Materials and methods: A community-based cross sectional study was conducted from May to June 2015 on 803 women who have had live births during the year (2014) preceding the data collection in the sub city. The multi-stage cluster sampling technique was used to select study participants. Data were collected by interviewer administered structured questionnaire, entered into EPI INFO version 7 and analyzed by SPSS Version 20. Bivariable and Multivariable logistic regression models were employed to see the presence and strength of the association between the dependent and independent variables by computing the odds ratios with a 95\% confidence intervals and $p$-values.

Results: The prevalence of postpartum family planning use was 80.3\% (95\% Cl: 74.5, 83.1). Marriage, (AOR 0.09, 95\% Cl: 0. 03, 0.22), menses resumption after birth, (AOR 2.12, 95\% Cl: 1.37, 3.41), length of time after delivery, (AOR 2.37, 95\% Cl: 1.18, $4.75)$, and history of contraceptive use before last pregnancy, (AOR $0.12,95 \% \mathrm{Cl}: 0.07,0.18$ ) were the factors associated with postpartum family planning use.

Conclusion: The prevalence of postpartum family planning use was high and the main factors associated with it were marriage, menses resumption, length of time after delivery, and history of previous contraceptive use. Therefore women should get appropriate information about the possibility of exposure to pregnancy prior to menses resumption by giving special emphasis to those who had no previous history of contraceptive use and exposure to the other identified factors.
\end{abstract}

Keywords: Postpartum period, Family planning, Kolfe Keranyo, Addis Ababa, Ethiopia

\section{Background}

Family planning (FP) is an essential component of health care provided during the antenatal period, immediately after delivery, and during the first postpartum year [1]. Postpartum family planning (PPFP) is defined as the prevention of unintended pregnancy and closely spaced

\footnotetext{
* Correspondence: almi_tsi@yahoo.com

Principal Investigator: Almaz Yirga Gebremedhin

${ }^{1}$ Pathfinder International, Addis Ababa, Ethiopia

Full list of author information is available at the end of the article
}

pregnancies during the first 12 months following childbirth [1]. The promotion of family planning in countries with high birth rates can avert 32\% of all maternal deaths and nearly $10 \%$ of childhood deaths [2]. Though family planning can avert that much maternal and childhood deaths, postpartum fertility and contraception are generally not well understood by policymakers, health service providers, or the women themselves [3]. Hence, promoting and providing PPFP is a vital issue as it saves the lives of mothers and children [1, 3, 4].

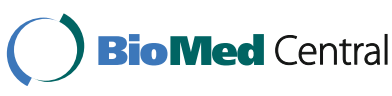

(c) The Author(s). 2018 Open Access This article is distributed under the terms of the Creative Commons Attribution 4.0 International License (http://creativecommons.org/licenses/by/4.0/), which permits unrestricted use, distribution, and reproduction in any medium, provided you give appropriate credit to the original author(s) and the source, provide a link to the Creative Commons license, and indicate if changes were made. The Creative Commons Public Domain Dedication waiver (http://creativecommons.org/publicdomain/zero/1.0/) applies to the data made available in this article, unless otherwise stated. 
Evidences showed that the use of family planning was low among postpartum women in spite of their unmet need for family planning [3]. There are two groups of PPFP methods, namely traditional and modern [5-7]. The traditional methods of PPFP include breastfeeding, abstinence, the calendar, and lactational amenorrhea [7]' While, modern methods involve intrauterine contraceptive devices (IUCD), implants (Implanon, Jadelle, sinoplant), injectables, progesterone-only oral contraceptives, coils, and condoms [7]. The effectiveness of the two groups of family planning methods (Modern versus Traditional) is not equal in that the failure rate of traditional methods is high [7]. The recommended time for the initiation of contraceptives in the postpartum period is 6 weeks after delivery [8]. Short and long pregnancy intervals have risks on perinatal outcomes, like increased risks of preterm birth, low birth weight, and small-for-gestational age $[9,10]$. All these evidences suggest that spacing pregnancies appropriately could help prevent such adverse perinatal outcomes and that PPFP use is of paramount importance.

The prevalence of contraceptive use among postpartum women varies from region to region in Ethiopia, as most women do not start taking contraceptives at the recommended time [11]. Even those who use PPFP rely on traditional, mainly lactational amenorrhea (LAM) that might pose the risk of unintended pregnancy. Therefore, initiating appropriate contraception in the postpartum period is important to avoid negative health outcomes.

Research conducted in Istanbul showed that only 34.0\% of mothers began contraceptive methods 5 months after childbirth [12]. Generally, women and family members did not perceive birth spacing as a priority, as women who deliver most recently were not using contraception [12, 13]. Another study conducted in Gondar showed that 48.8\% of mothers used PPFP [14].

A variety of literature showed that factors like maternal age $[15,16]$, employment status [17], religion or culture $[4,18-21]$, lack of awareness of family planning methods $[14,20,22]$, male involvement $[4,18,21]$, extended family [18, 23], death of child [17], antenatal care follow up [24], inaccessibility of family planning methods $[18,20]$, and fear of side effects [18] were some of the factors affecting PPFP use among women in the postpartum period [4].

Therefore, by considering the above situation, this study set out to assess postpartum family planning use and its associated factors among women in extended postpartum period in Kolfe Keranyo sub-city, Addis Ababa.

\section{Methods}

\section{Study design}

A community-based cross-sectional study design was employed to obtain data from women who had live births 12 months prior to the survey.

\section{Study period and study area}

This study was conducted from May to June 2015 in Kolfe Keranyo sub-city which is located south-west of Addis Ababa. The sub-city is divided into 15 administrative areas (districts). According to the 2014 population projection estimates, there were 500,163 residents in the sub-city, with half of them being women [13]. In addition, there were twelve health centres, 2 health posts and no hospital at Kolfe Keranyo sub-city.

\section{Source and study population}

The source population of this study was women who had live births 12 months prior to the survey with the exception of those who were unable to respond during the survey in Kolfe Keranyo sub- city.

\section{Sample size determination and sampling procedure}

The sample size was determined using the single population proportion formula, considering the following assumptions: Prevalence $(\mathrm{P})$ of family planning use during postpartum period $=52.5 \%$ [13], margin of error $(\mathrm{w})$ $=5 \%$, design effect of $2,10 \%$ non response rate, $Z_{\alpha / 2}=$ 1.96 at $95 \%$ confidence interval. The total sample calculated was 849 .

A multistage cluster sampling technique was used to select the participants. First, out of the fifteen districts of Kolfe Keranyo sub-city, four were chosen by the simple random sampling technique (lottery method). Considering proportion, sixteen ketanas (smallest administration units of sub-cities) were selected using the lottery method. Then, the total sample size was distributed proportionally to each cluster (ketana). Postpartum women in the selected ketenas were interviewed through house to house visits until the predetermined sample size allocated to each cluster was completed. The data were collected using an interviewer administered questionnaire by ten BSc Graduate nurses who had previous experience in data collection, and the process was supervised by two experts who had Master's degree in Public Health and previous experience in research supervision. The collected data were checked for completeness daily.

\section{Data quality assurance}

To assure the reliability and validity of the questionnaire, a pre-test was conducted on 44 individuals living outside the study area. Training was given to data collectors and supervisors for 1 day before data collection.

\section{Operational definition}

Extended postpartum period: a 12-month period after a live birth.

Postpartum women: women who had live births within the past 1 year prior to date of data collection. 
Postpartum family planning use: When a postpartum woman reported using any family planning methods (pills, intrauterine device, injectable, condom, sterilization, or implants), or traditional (breastfeeding or calendar methods) during the 12-month following her most recent childbirth.

\section{Ethical considerations}

Ethical clearance was obtained from the Institutional Review Board (IRB) of the Institute of Public Health, the University of Gondar. Permission letters were obtained from Addis Ababa city and Kolfe Keranyo subcity administrations respectively. Participants were informed about the objectives of the study and reassured about the confidentiality of the findings. A written consent was obtained from each participant.

\section{Data processing and analysis}

The data were checked for completeness and coded manually. EPI-INFO version 7 and SPSS version 20 were used for data entry and analysis, respectively. Descriptive statistics, such as frequencies and percentages were computed to describe the study population in relation to relevant variables. Bivariate and Multivariable logistic regression analyses were carried out to see the presence of association between dependent and the independent variables. Variables with $p$-values of $<0.2$ in the Bivariate analysis were further fitted to multivariable logistic regression analysis. Adjusted odds ratios with 95\% confidence intervals were computed and variables with $p$ - values of $<0.05$ in the multivariable analysis were considered as statistically significant.

\section{Results}

\section{Socio-demographic characteristics}

In this study, 803 postpartum women participated with a response rate of $94.9 \%$. Majority of respondents, 675(84.1\%), were aged 20-34 years. Regarding respondents marital status, religion, and occupation, 748(93.2\%) were married, 454(56.5\%) were Orthodox Christians, and 468(58.3\%) were housewives. Concerning their educational status, $90(11.1 \%)$ of the respondents did not have any formal education, and one-fourth of them, 197(24.5\%) were grade 12 and above (Table 1 ).

\section{Fertility and reproductive characteristics}

Among the respondents, 535(66.6\%) had one or two children and about half, 401(49.9\%), had a lapse of 6 months since their delivery. The majority, 719(89.5\%), reported that their recent pregnancy was planned, and $652(81.2 \%)$ desired to have a birth interval of more than 2 years. More than half, 442(55.0\%), of the respondents said that menses had not resumed after their recent birth, and 748(93.2\%) reported they were breastfeeding at the time of the survey. Slightly more than threefourths, 629(78.3\%), had histories of family planning use before their last pregnancies (Table 2).

\section{Postpartum family planning method use}

In this study, the prevalence of PPFP use was $80.3 \%$ (95\% CI: $74.5,83.1)$ and the most preferable method used by $221(32.2 \%)$ of the women was the injectable (Fig. 1).

\section{Factors associated with postpartum family planning use}

The result of the multivariable analysis showed that marital status, length of time after delivery, menses resumption after recent birth, and history of family planning use before current pregnancy were significantly associated with PPFP use. Unmarried women were 91.0\% less likely to use family planning methods as compared to married ones (AOR $=0.09,95 \% \mathrm{CI}$ : 0.03, 0.22). Women with a time lapse of over 6 months since their delivery were two times more likely to use family planning method as compared to women who had less than that $(\mathrm{AOR}=2.37,95 \% \mathrm{CI}: 1.18,4.75)$. Women who had had menses resumption after recent birth were two times more likely to use family planning method than who had not $(\mathrm{AOR}=2.12,95 \% \mathrm{CI}$ : $1.37,3.41)$. Women who had no history of contraceptive use before their last birth were $88 \%$ less likely to use family planning method during the postpartum period compared to those who had $(\mathrm{AOR}=0.12,95 \%$ CI: $0.07,0.18)$ (Table 3$)$.

\section{Discussion}

Postpartum period is an entry point to initiate family planning methods for mothers, but usually it is a missed opportunity. The prevalence of postpartum family planning method (PPFP) use in this study was $80.3 \%$ (95\% CI: 74.5, 83.1\%). This finding is in line with that of a study conducted in Nichisti District Hospital, Malawi where the prevalence of PPFP was 75\% [25]. This similarity might be due to the similarity of participants in the two studies in some socio demographic characteristics. For instance, the proportion of women who were married in this study was $93.2 \%$, and in the Malawi study it was $93.3 \%$ [25]. Moreover, the educational status of the two participants was almost similar.

Postpartum contraceptive use in this study was higher than those of other studies conducted in Ethiopia, for example the 2011 EDHS, Gondar town, Dabat, Axum, and Somali region reported 55, 48.4, 10.3, 48, and 12.3\%, respectively [11, 14, 26-29]. It was also higher than the findings of studies conducted in Uganda (28\%) [28] and Rural Uganda (25.0\%) [30].

The discrepancy could be due to time gap of studies and the presence of some dissimilar socio-demographic and reproductive characteristics among participants. For instance, literature documented that educational level 
Table 1 Socio-demographic characteristics of women in the first year of postpartum period in Kolfe Keranyo sub city, Addis Ababa, 2015

\begin{tabular}{llll}
\hline Variables & & Frequency & Percent \\
\hline Age & & & \\
& $15-19$ & 16 & 2.0 \\
& $20-34$ & 675 & 84.1 \\
& $35-49$ & 112 & 13.9
\end{tabular}

Educational status

$\begin{array}{ll}\text { No formal education } & 89 \\ \text { Primary } & 275 \\ \text { Secondary } & 242 \\ \text { Above Secondary } & 197\end{array}$

Marital status

Married 748

Ethnicity

$\begin{array}{ll}\text { Amhara } & 32 \\ \text { Oromo } & 178 \\ \text { Tigre } & 70 \\ \text { Gurage } & 142 \\ \text { Siltie } & 51 \\ \text { Other } & 41\end{array}$

Occupation

$\begin{array}{ll}\text { Housewife } & 468 \\ \text { Merchant } & 84 \\ \text { Daily Labourer } & 22 \\ \text { Gov/ Private Employee } & 195 \\ \text { Other } & 34\end{array}$

Religion

$\begin{array}{ll}\text { Orthodox } & 454 \\ \text { Catholic } & 31 \\ \text { Protestant } & 109 \\ \text { Muslim } & 209\end{array}$

Spouse's educational status (773)

No formal education

Primary

Secondary

Above Secondary

Spouse's occupation(773)

Merchant

Daily Labourer

Gov/ Private Employee

Other
258

210

287

256

160

89

275

42

97

5

\section{1}

78

0

42

1

41

68

84

22

195

4

209

(8)

8

10

245

112

$$
24.5
$$

40.0

210

287

20.7
Table 2 Fertility and reproductive characteristics of women in the first year of postpartum period in Kolfe Keranyo sub city, Addis Ababa, 2015

\begin{tabular}{llll}
\hline Variables & Frequency & & Percent \\
\hline Parity & & & \\
& $1-2$ & 535 & 66.6 \\
& $3-4$ & 243 & 30.3 \\
& $\geq 5$ & 25 & 3.1
\end{tabular}

Duration of month since delivery

$\begin{array}{lll}<6 \text { Months } & 271 & 33.7 \\ 6 \text { Months } & 131 & 16.3\end{array}$

Planned birth

Preferred birth space

$\begin{array}{lll}\text { Yes } & 719 & 89.5 \\ \text { No } & 84 & 10.5\end{array}$

$\leq 2$ Years

$>2$ Years

I Don't Know

Number of children wish to have

$\begin{array}{lll}\leq 4 & 443 & 55.2 \\ >4 & 46 & 5.7 \\ & 314 & 39.1\end{array}$

Health education about FP during ANC

$\begin{array}{lll}\text { Yes } & 365 & 45.5 \\ \text { No } & 438 & 54.5\end{array}$

Menses before pregnancy

$\begin{array}{lll}\text { Regular } & 676 & 84.2 \\ \text { Irregular } & 127 & 15.8\end{array}$

Menses after delivery

Visit HC after delivery

$\begin{array}{lll}\text { Yes } & 361 & 45.0 \\ \text { No } & 442 & 55.0\end{array}$

$\begin{array}{lll}\text { Yes } & 649 & 80.8\end{array}$

$\begin{array}{lll}\text { No } & 154 & 19.2\end{array}$

Currently breastfeeding

$\begin{array}{lll}\text { Yes } & 748 & 93.2 \\ \text { No } & 55 & 6.8\end{array}$

Number of FP you know

$\begin{array}{lll}\leq 4 & 328 & 40.8 \\ \geq 4 & 475 & 59.2\end{array}$

History of FP use before current pregnancy Yes 


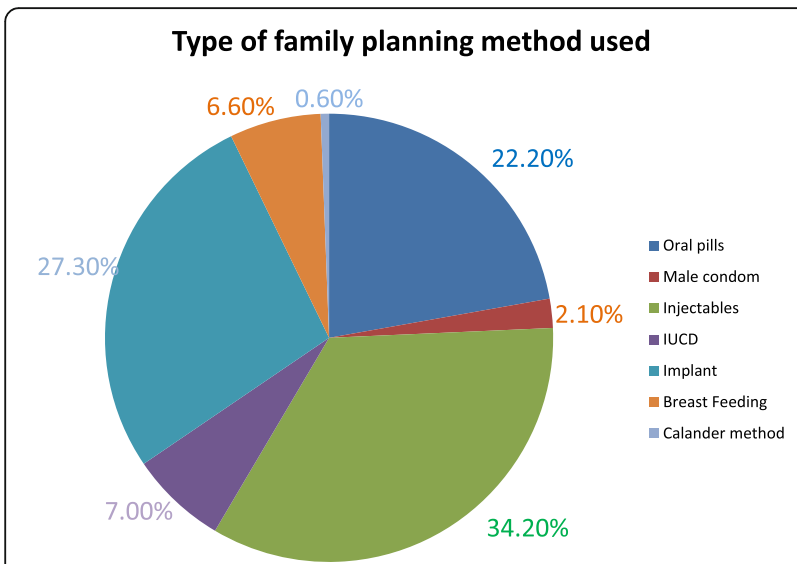

Fig. 1 Type of family planning methods used by women in the first year postpartum period in Kolfe Keranyo sub city, Addis Ababa, Ethiopia, 2015

has a direct relationship with PPFP use [11, 13, 31, 32]. The possible reason for the difference in the prevalence of PPFP might be the difference in educational level of study participants. For example, in the study conducted in Gondar town, the proportion of women who did not have any formal education was higher $(21.9 \%)$ than that of this study (11.1\%). The same was true with the study conducted at Dabat district in which the proportion of women who did not have formal education was $64.4 \%$ [26], higher than what was seen in this study. Meanwhile, the proportion of participants with tertiary education in this study was higher (24.5\%) than that of the study conducted in Gondar (20.6\%) [14]. The proportion of study participants who had higher education was lower in the studies conducted in Dabat, Ethiopia (1.8\%) [26] and Axum (12.2\%) [27] than that of this study (24.5\%). The proportion of women who had secondary education and above was higher $(54.6 \%)$ in this study compared to (23.7\%) of Uganda [28] and $42.6 \%$ of rural Uganda [30].

The other possible reasons for the differences between this work and the study done in Axum might be variations in spousal educational status and birth intention, not only women's educational level, but also that of their husbands can take part in PPFP use. If spouses are educated, they can understand the benefits of having adequate space between births and encourage and advise on the use of family planning methods, which could contribute to the uptake of PPFP.

The proportion of partners educational status in this study was higher than that of Axum. The proportion of mothers who wanted to have birth intervals of less than or equal to 2 years was higher among the participants in Axum (24.2\%) than in this study (2.1\%) [27].

Marital status of women might have contributions to the observed differences in the prevalence of PPFP use.
If a woman is married, she may have early postpartum sexual contact than those who are not married. So, there may be differences in risk perception between the two groups of women that risk perception relating to unwanted or mistimed pregnancy is expected to be high among married women than none married ones. The proportion of our participants who were married was higher (93.2\%) than that of the study done in Uganda [28]. Another possible reason for the difference in PPFP use among postpartum women might be differences in perinatal service utilization. Women who had history of antenatal and postnatal care visits might have better chances of getting counselling about contraceptive use. The proportion of mothers who had postnatal care visits was higher in this study $(80.8 \%)$ than the study done in Dabat, Ethiopia (5.7\%) [26].

However, the uptake of PPFP in this study was lower than those of studies conducted in Kenya, Nairobi (95.2\%) and South Africa (89.0\%) [21,33]. The difference could be due to the presence of socio-economic differences, cultural variations, and service accessibility.

Unmarried women were $91.0 \%$ less likely to use PPFP methods than married ones. This could be due to the fact that unmarried women may be less likely to be sexually active than married ones which might reduce their demand and use of PPFP methods. It might also be explained in terms of the fact that married women might have more access to different PPFP methods compared to unmarried ones.

In this study, women whose menses resumed after the recent birth were two times more likely to use the PPFP method than women whose menses did not (AOR 2.22, 95\% CI: 1.39, 3.51). This finding was in line with those of studies conducted in Gondar town and Axum Ethiopia, and in Malawi [14, 16, 27]. That is because most women may tend to believe that the risk of pregnancy is linked to only menses resumption, and might not take family planning methods during the postpartum period.

Duration in months after delivery was found to have a significant association with the use of PPFP. The longer the duration after delivery, the better the use of contraceptives. This finding was similar with the results of studies conducted in Gondar town and Somali region $[14,29]$. The possible explanation could be that as the duration of postpartum increased the proportion of women who start sexual activity raise hence, women might suspect pregnancy during the sexual exercise, and decide to use PPFP.

Women who had history of family planning method use prior to their last pregnancy were also found to use contraceptives in their postpartum period more than those who had no such history. This result was similar with that of a study conducted in rural Uganda, where women who 
Table 3 Multivariate analysis showing factors associated with PPFP use in Kolfe Keranyo sub city, Addis Ababa, 2015

\begin{tabular}{|c|c|c|c|c|}
\hline \multirow[t]{2}{*}{ Variables } & \multicolumn{2}{|l|}{ PPFP use } & \multirow[t]{2}{*}{ COR 95\% Cl } & \multirow[t]{2}{*}{ AOR 95\%Cl } \\
\hline & $\begin{array}{l}\text { Yes } \\
\text { Number (\%) }\end{array}$ & $\begin{array}{l}\text { No } \\
\text { Number (\%) }\end{array}$ & & \\
\hline \multicolumn{5}{|l|}{ Age in years } \\
\hline $15-19$ & $10(62.5)$ & $6(37.5)$ & 1 & 1 \\
\hline $20-34$ & 402(59.6) & $273(40.4)$ & $1.13(0.84,2.01)$ & $0.30(0.20,4.70)$ \\
\hline $35-39$ & $72(64.3)$ & $40(35.7)$ & $0.93(0.45,1.70)$ & $0.61(0.70,3.73)$ \\
\hline \multicolumn{5}{|l|}{ Marital status } \\
\hline Married & $627(83.3)$ & $121(16.2)$ & 1 & 1 \\
\hline Unmarried & $18(32.7)$ & $37(67.3)$ & $10.65(0.96,11.01)$ & $0.09(0.03,0.22)^{*}$ \\
\hline \multicolumn{5}{|l|}{ Educational Status } \\
\hline No formal education & $26(29.2)$ & $63(70.8)$ & 1 & 1 \\
\hline Primary & $116(42.2)$ & 159(57.8) & $0.57(0.42,2.00)$ & $1.72(0.53,5.49)$ \\
\hline Secondary & 194(80.2) & $48(19.8)$ & $0.10(0.01,3.79)$ & $0.68(0.98,2.40)$ \\
\hline Above Secondary & 145(73.6) & $52(26.4)$ & $0.15(0.11,4.50)$ & $1.60(0.85,3.02)$ \\
\hline \multicolumn{5}{|l|}{ Time in months since delivery } \\
\hline$<6$ & 192(70.8) & $79(29.2)$ & 1 & 1 \\
\hline 6 & $107(81.7)$ & $24(18.3)$ & $0.55(0.24,1.39)$ & $2.38(1.19,4.80)^{*}$ \\
\hline$>6$ & $346(86.3)$ & $55(13.7)$ & $0.39(0.17,0.82)$ & $2.73(1.73,4.52)^{*}$ \\
\hline \multicolumn{5}{|l|}{ Occupation } \\
\hline House wife & 157(33.6) & $311(66.4)$ & 1 & 1 \\
\hline Merchant & $43(51.2)$ & $41(48.8)$ & $0.48(0.22,1.59)$ & $1.40(0.91,3.52)$ \\
\hline Daily laborer & $8(36.4)$ & 14(63.6) & $0.88(0.21,3.01)$ & $1.30(0.72,3.03)$ \\
\hline Government/Private employee & 135(69.2) & $60(30.8)$ & $0.22(0.10,1.51)$ & $0.83(0.61,4.50)$ \\
\hline Other ${ }^{a}$ & $8(23.5)$ & $26(76.5)$ & $1.64(0.38,1.20)$ & $1.51(0.87,2.12)$ \\
\hline \multicolumn{5}{|l|}{ History of previous FP use } \\
\hline Yes & $557(88.6)$ & $72(11.4)$ & 1 & 1 \\
\hline No & $88(50.6)$ & $86(49.4)$ & $7.56(0.95,8.01)$ & $0.12(0.07,0.18)^{*}$ \\
\hline \multicolumn{5}{|l|}{ Menses resumption after delivery } \\
\hline Yes & $266(73.7)$ & $95(26.3)$ & 1 & 1 \\
\hline No & $379(85.7)$ & $63(14.3)$ & & $2.07(1.38,3.41)^{*}$ \\
\hline
\end{tabular}

${ }^{*} P<0.05=$ Significant ${ }^{2}$ House servants, Jobless

had previous history of family planning method use were nearly two times more likely to use family planning methods compared to their counter parts [30]. This could be explained by the fact that women who had history of previous family planning method use might have more knowledge, better attitude, and practice regarding the use of family planning methods compared to those who had not.

The proportion of women who had no history of previous contraceptive use was $88 \%$ less likely to use PPFP use than those who had previous experience. This might be explained by the fact that women who had previous history of contraceptive use might have better attitude and practice with regard contraceptives as compared to those who had not.
Since this was a cross-sectional study, it shares the limitations of the study design. Including women within the first 6 weeks postpartum was one of the shortcomings of this study. Moreover, as the study mainly focussed on individual level factors, it is recommended that researchers include factors relating to the health system and service providers in the future.

\section{Conclusion}

This study found that the prevalence of postpartum family planning use was high. Marital status (marriage), number of months after delivery, history of menses resumption after recent birth, and history of family planning use before the current pregnancy were factors significantly associated with postpartum contraceptive use. 


\section{Abbreviations}

ANC: Antenatal Care; AOR: Adjusted Odds Ratio; Cl: Confidence Interval; COR: Crude Odds Ratio; DHS: Demographic and Health Survey; FP: Family Planning; HC: Health Centre; OR: Odds Ratio; PPFP: Postpartum Family Planning; RTT: Research and Technology Transfer Core Process; SPSS: Statistical Package for the Social Sciences; WHO: World Health Organization

\section{Acknowledgements}

The authors acknowledge the Institute of Public Health, College of Medicine and Health Sciences, University of Gondar. Besides the authors thank staffs of Addis Ababa regional health bureau, kolfe keranyo sub city health office staffs and the four District Health officers who gave permission to do the research. Moreover the authors thank all the study participants, data collectors and supervisors for their participation and facilitation during the field work throughout the study time.

\section{Funding}

No funding has been obtained from any source to carry out this study.

\section{Availability of data and materials}

All the dataset supporting the conclusions of this article is included within the article.

\section{Authors' contributions}

AYG, YK and AAG: designed, acquired the data; analyzed and interpreted the study. YAH and AAG prepared the manuscript. All authors read and approved the final manuscript.

\section{Ethics approval and consent to participate}

Ethical clearance was obtained from the institution review board of Institute of Public Health, University of Gondar. Moreover permission letter was obtained from Kolfe Keranyo sub city administration authorities. Written consent was obtained from each study subjects and respondents were also informed that they have the right to refuse or discontinue participation at any time. Information was recorded anonymously to maintain confidentiality and privacy of respondent's.

\section{Consent for publication}

Consent to publish was obtained from the study subjects.

\section{Competing interests}

The authors declare that they have no competing interests.

\section{Publisher's Note}

Springer Nature remains neutral with regard to jurisdictional claims in published maps and institutional affiliations.

\section{Author details}

${ }^{1}$ Pathfinder International, Addis Ababa, Ethiopia. ${ }^{2}$ Department of Epidemiology and Biostatistics, Institute of Public Health, College of Medicine and Health Sciences, University of Gondar, Gondar, Ethiopia. ${ }^{3}$ Department of Reproductive Health, Institute of Public Health, College of Medicine and Health Sciences, University of Gondar, Gondar, Ethiopia.

Received: 6 June 2017 Accepted: 7 December 2017

Published online: 05 January 2018

\section{References}

1. WHO: Programming strategies for postpartum family planning. ISBN 97892 41506496 (NLM classification: WA 550). Geneva: World Health Organization. 2013

2. Cleland J, Bernstein S, Ezeh A, Faundes A, Glasier A, Innis J. Family planning: the unfinished agenda. Lancet (London, England). 2006;368(9549):1810-27.

3. Borda MR, Winfrey W, McKaig C: Return to sexual activity and modern family planning use in the extended postpartum period: an analysis of findings from seventeen countries. Afr J Reprod Health 2010, 14(4 Spec no. ):72-79.

4. Eliason S, Baiden F, Quansah-Asare G, Graham-Hayfron Y, Bonsu D, Phillips J, Awusabo-Asare K. Factors influencing the intention of women in rural Ghana to adopt postpartum family planning. Reprod Health. 2013;10:34.
5. Rossier C, Hellen J. Traditional birthspacing practices and uptake of family planning during the postpartum period in Ouagadougou: qualitative results. Int Perspect Sex Reprod Health. 2014;40(2):87-94.

6. MoH FDRoE: Health Sector Development Programme IV: 2010/11-2014/15. 2010

7. WHO: New health resource to improve access to family planning for women after childbirth: interventions address health service gaps for this often overlooked group of women. 2013.

8. Randel A. CDC updates recommendations for contraceptive use in the postpartum period. Am Fam Physician. 2011;84(12):1422-5.

9. Conde-Agudelo A, Rosas-Bermudez A, Kafury-Goeta AC. Birth spacing and risk of adverse perinatal outcomes: a meta-analysis. JAMA. 2006;295(15): 1809-23.

10. Conde-Agudelo A, Rosas-Bermudez A, Kafury-Goeta AC. Effects of birth spacing on maternal health: a systematic review. Am J Obstet Gynecol. 2007:196(4):297-308

11. Demographic and Health Survey: Addis Ababa. Ethiopia and Calverton, Maryland, USA: central statistics agency and ORC macro 2011.

12. Bulut A, Turan JM. Postpartum family planning and health needs of women of low income in Istanbul. Stud Fam Plan. 1995;26(2):88-100.

13. CSA; Federal Democratic Republic of Ethiopia, Centera; Statistical Agency. 2013:28.

14. Abera Y, Mengesha ZB, Tessema GA. Postpartum contraceptive use in Gondar town, Northwest Ethiopia: a community based cross-sectional study. BMC Womens Health. 2015;15:19.

15. Cowman W, Hardy-Fairbanks AJ, Endres J, Stockdale CK. A select issue in the postpartum period: contraception. Proceedings in Obstetrics and Gynecology. 2013;3(2):1-15.

16. Bwazi C, Maluwa A, Chimwaza A, Pindani M. Utilization of postpartum family planning services between six and twelve months of delivery at Ntchisi District hospital. Malawi Health. 2014;2014

17. Gebreselassie T, Rutstein SO, Mishra V. Contraceptive use breastfeeding amenorrhea and abstinence during the postpartum period: an analysis of four countries. 2008

18. Naanyu V, Baliddawa J, Peca E, Karfakis J, Nyagoha N, Koech B. An examination of postpartum family planning in western Kenya: "I want to use contraception but I have not been told how to do so". Afr J Reprod Health. 2013;17(3):44-53.

19. Sathiya Susuman A, Bado A, Lailulo YA. Promoting family planning use after childbirth and desire to limit childbearing in Ethiopia. Reprod Health. 2014; 11:53.

20. Grimes DA, Lopez LM, Schulz KF, Van Vliet HA, Stanwood NL. Immediate post-partum insertion of intrauterine devices. Cochrane Database Syst Rev. 2010;(5):Cd003036

21. Wairagu AM. Determinants of family planning option among women aged 15-24 years seeking postnatal Care Services in Nairobi County. Kenya: KENYATTA UNIVERSITY; 2013.

22. Speizer IS, Fotso JC, Okigbo C, Faye CM, Seck C. Influence of integrated services on postpartum family planning use: a cross-sectional survey from urban Senegal. BMC Public Health. 2013:13:752.

23. Bizuneh $G$, Shiferaw S, Melkamu Y: Unmet need and evaluation of programme options to meet unmet need for contraception in Ethiopia 2000 and 2005. Further analysis of the 2000 and 2005 Ethiopia demographic and health surveys. 2008

24. Page HJ, Lesthaeghe R: Child-spacing in tropical Africa: traditions and change. 1981.

25. Kopp DM, Rosenberg NE, Stuart GS, Miller WC, Hosseinipour MC, Bonongwe P, Mwale M, Tang JH: Patterns of contraceptive adoption, continuation, and switching after delivery among Malawian women. PLoS One 2017, 12(1): e0170284.

26. Mengesha ZB, Worku AG, Feleke SA. Contraceptive adoption in the extended postpartum period is low in Northwest Ethiopia. BMC pregnancy and childbirth. 2015:15:160

27. Abraha TH, Teferra AS, Gelagay AA. Postpartum modern contraceptive use in northern Ethiopia: prevalence and associated factors. Epidemiology and health. 2017;39:e2017012.

28. Rutaremwa G, Kabagenyi A, Wandera SO, Jhamba T, Akiror E, Nviiri HL. Predictors of modern contraceptive use during the postpartum period among women in Uganda: a population-based cross sectional study. BMC Public Health. 2015;15:262

29. Nigussie AT, Girma D, Tura G. Postpartum family planning utilization and associated factors among women who gave birth in the past 12 months, 
Kebribeyah Town, Somali Region, Eastern Ethiopia. J Women's Health Care. 2016;5:340. doi:https://doi.org/10.4172/2167-0420.1000340.

30. Sileo KM, Wanyenze RK, Lule H, Kiene SM. Determinants of family planning service uptake and use of contraceptives among postpartum women in rural Uganda. Int J Public Health. 2015;60(8):987-97.

31. Ethiopia., MEASURE/DHS+ OM: Ethiopia Demographic and Health Survey, 2000: Central Statistical Authority; 2001.

32. Demographic E. Health survey 2005 Addis Ababa and Calverton: MD, USA Central Statistical Agency and ORC Macro; 2006.

33. Crede S, Harries J, Constant D, Hatzell Hoke T, Green M, Moodley J. Is 'planning' missing from our family planning services? S Afr Med J. 2010; 100(9):579-80.

Submit your next manuscript to BioMed Central and we will help you at every step:

- We accept pre-submission inquiries

- Our selector tool helps you to find the most relevant journal

- We provide round the clock customer support

- Convenient online submission

- Thorough peer review

- Inclusion in PubMed and all major indexing services

- Maximum visibility for your research

Submit your manuscript at www.biomedcentral.com/submit
Biomed Central 